\title{
Screening for tylosin and other antimicrobial residues in fresh and fermented (nono) cow milk in Delta state, South-South, Nigeria
}

\author{
Onwumere-Idolor Onyinye Stella ${ }^{1}$, Ekene Vivienne Ezenduka² ${ }^{\mathbb{D}}$ and Nwanta John Anaelom²
}

1. Public Health specialty, University of Nigeria, Study Center, College of Veterinary Surgeons, Nigeria; 2. Department of Veterinary Public Health and Preventive Medicine, University of Nigeria, Nsukka, Nigeria.

Corresponding author: Ekene Vivienne Ezenduka, e-mail: ekene.ezenduka@unn.edu.ng

Co-authors: OOS: onyiionwumere@yahoo.com, NJA: john.nwanta@unn.edu.ng

Received: 04-10-2019, Accepted: 27-01-2020, Published online: 12-03-2020

doi: www.doi.org/10.14202/vetworld.2020.458-464 How to cite this article: Stella OO, Ezenduka EV, Anaelom NJ (2020) Screening for tylosin and other antimicrobial residues in fresh and fermented (nono) cow milk in Delta state, South-South, Nigeria, Veterinary World, 13(3): 458-464.

\begin{abstract}
Background and Aim: Milk is a food that contains almost all the essential nutrients needed for growth and maintenance for both young and old animals and man. Since quite nutritious and in high demand, dairy products should be free of both chemical and biological contaminants. Unfortunately, antibiotics used in the treatment of infectious diseases in dairy cattle are often seen in their products if withdrawal periods of those drugs are not observed before milking. This study aimed to detect the presence of antibiotics and the level of tylosin in fresh and fermented (nono) milk from cows in Delta state, Nigeria.

Materials and Methods: Two hundred and five samples comprising 126 fresh milk and 79 fermented milk (nono) were sampled from Kwale, Ozoro, and Oleh representing one senatorial district of Delta state, South-South Nigeria. They were screened for the presence of tylosin and other antimicrobial residues using four-plate test and tylosin was confirmed with high-performance liquid chromatography.

Results: Antibiotic residues were obtained in $76 \%$ and $85 \%$ of fresh milk and nono, respectively. Tylosin residue was also detected in $24 \%$ fresh milk and $11 \%$ nono samples at mean concentrations of $14.64 \pm 0.69 \mu \mathrm{g} / 1$ and $7.97 \pm 0.23 \mu \mathrm{g} / 1$, respectively. The mean concentrations of tylosin from both milk types were below the recommended maximum residue limit (MRL) of $50 \mu \mathrm{g} / \mathrm{l}$ in dairy.

Conclusion: High prevalence of antimicrobial residues in fresh milk and nono shows that consumers in the study area are predisposed to health hazards due to the presence of residues of different antibiotics in fresh milk and nono. Although tylosin was confirmed in both milk products, the mean concentrations were below the MRL. However, it is still very vital to resort to the observance of withdrawal periods and avoid gross misuse of antimicrobials. It is also necessary to emphasize the need for effective prevention of infectious diseases and most importantly create awareness and establish a national antibiotic residue monitoring program in Nigeria.
\end{abstract}

Keywords: antimicrobials, dairy, milk, residue, tylosin.

\section{Introduction}

Milk is one of the most balanced food compositions which provide protein, calcium, fats, mineral potassium, phosphorus, vitamins, lactose, and amino acids for growth, maintenance, and development of body tissues. Therefore, it is an essential part of a daily diet for all ages: Children and the elderly [1]. Food for human consumption should be free of all types of compounds of adverse effects on human health. These harmful compounds are not restricted to microorganisms and biological factors and toxins excreted from them, but all types of chemicals that directly or indirectly contaminate foodstuff are also highly important. Unlike microbial infections and

Copyright: Stella, et al. Open Access. This article is distributed under the terms of the Creative Commons Attribution 4.0 International License (http://creativecommons.org/licenses/by/4.0/), which permits unrestricted use, distribution, and reproduction in any medium, provided you give appropriate credit to the original author(s) and the source, provide a link to the Creative Commons license, and indicate if changes were made. The Creative Commons Public Domain Dedication waiver (http://creativecommons.org/ publicdomain/zero/1.0/) applies to the data made available in this article, unless otherwise stated. poisoning, complications of chemical poisonings often take effect in the long term.

In Nigeria, dairy industry is an important component of agribusiness sector of the economy with great economic, nutritional, and social endeavor [2], and as the largest milk producer in West Africa, Nigeria has the potential of being a major milk producer in Africa with total annual demand estimated at 1.45 billion liters [3]. Most dairy cattle in Nigeria are reared by the Fulani herdsmen, who most likely engage in indiscriminate use of veterinary drugs for prophylactic and therapeutic purposes in their cattle [4]. This is largely due to the nomadic system of cattle rearing where cattle are moved through the bush and road paths to different parts of the country, with limited access to veterinary clinics and veterinarians. They buy these drugs which are readily available over the counter and administer to the animals themselves with neither prescription nor correct dosage [5].

Antimicrobials are used in dairy cattle production primarily to treat/prevent diseases, increase milk production, or improve feed efficiency by administering 
at low doses for extended periods [6]. However, widespread use could lead to persistent residues in edible parts such as muscle (meat), organs, egg, and milk obtained from treated animals [7]. These residues may include the non-altered parent residue as well as metabolites and/or conjugates [8]. The presence of these residues is usually attributed to non-observance of withdrawal periods before slaughter and milking, which is mainly due to undesirable practices such as unregulated and indiscriminate use of drugs and lack of awareness of the proper use of these antibiotics $[9,10]$. There is also the undocumented claim that due to the lack of refrigeration, antimicrobials are added to fresh milk to avoid the activities of spoilage bacteria. Fresh milk and milk products are important products of the Fulani agro-pastoral and even other smallholders peri-urban system of Nigeria [11]. They are produced and processed by traditional herdsmen and milkmaids for local consumption.

Antibiotic residues in milk and products are of great concern to dairy farmers, milk processors, consumers, and regulatory agencies. To ensure food safety for consumers, several regulatory authorities around the world, including the European Food Safety Agency, Food and Drug Administration, and USA Codex Alimentarius, established tolerance (safe) levels of antibiotic residues in milk [12]. Exceeding tolerance levels not only present potential health risks to the consumer but also interfere with fermentation processes through the inhibition of starter culture during milk processing for the production of cheese and yogurt [13]. The concern of drug residues in milk to human health is due to their association with allergies and life-threatening hypersensitive reactions [14,15], development of resistant strains of microorganisms [16], and carcinogenic and mutagenic effects [17]. Different methods were developed to detect antibiotics in milk, screening and chromatographic techniques. Microbiological methods are basically used for screening, although recommended as the conventional and official method used due to its high throughput and simple procedure, it lacks specificity and can at most, produces a semi-quantitative result [18]. Chromatographic methods were, therefore, developed to confirm the presence and quantitate the concentration of incriminating antibiotics [19].

Several studies have reported the presence of antibiotic residues in different foods of animal origin $[4,20,21]$. However, limited information is available on the occurrence of tylosin residue in bovine milk in Nigeria. In common with many other developing countries, the awareness of the extent of drug residues in foods of animal origin, especially milk has not been very well created to stakeholders. In effect, policy-makers remain unaware of the extent of the problem, suggesting that no quality assurance program is put in place to checkmate this issue.

This study aimed to detect the presence of antibiotics and the level of tylosin in fresh and fermented (nono) milk from cows in Delta state, Nigeria.

\section{Materials and Methods}

\section{Ethical approval and informed consent}

Informed consents of the herdsmen and management of milk collection centers in the three local government areas (LGAs) were obtained. Milk samples were collected from milk collection centers.

\section{Study area}

The study was carried out in three LGAs of Delta State, South-South Nigeria (Figure-1). The LGAs comprise Kwale representing Ndokwa West, Ozoro representing Isoko North, and Oleh representing Isoko South.

\section{Study design}

A cross-sectional survey was carried out using both qualitative and quantitative approaches to

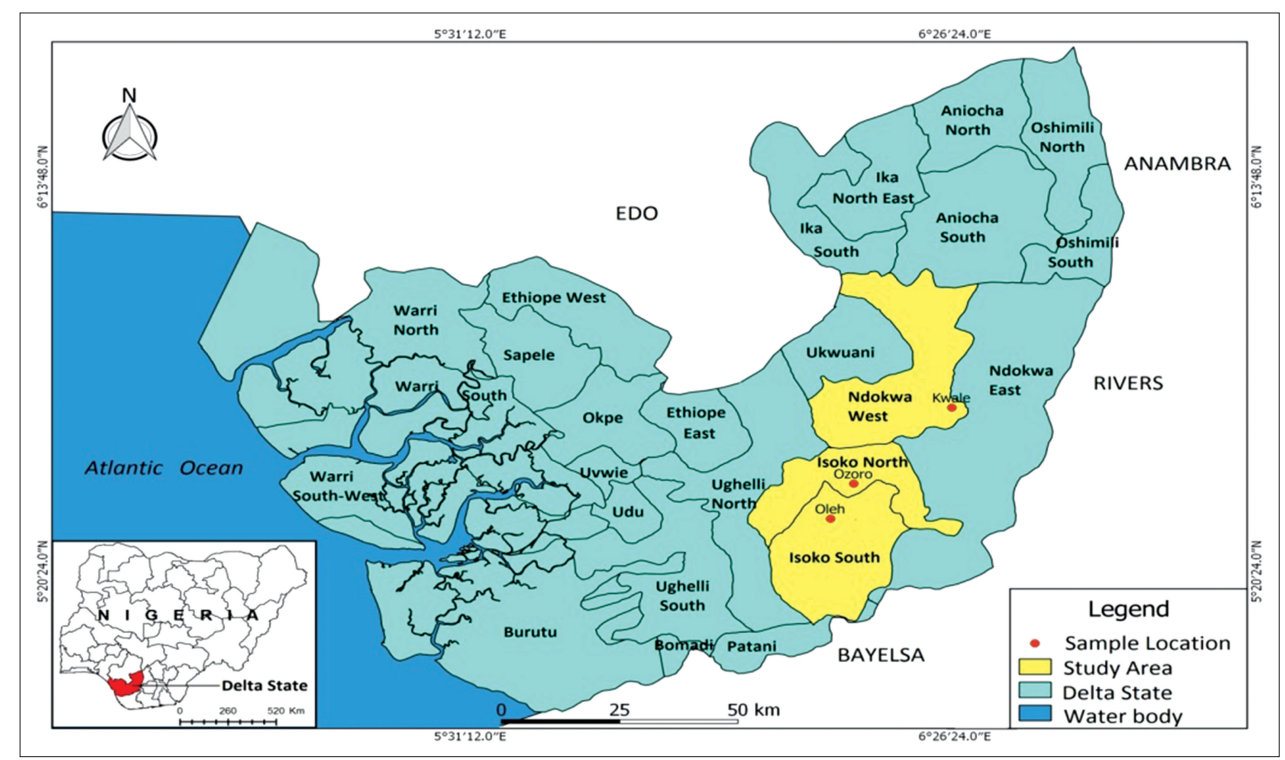

Figure-1: Map of the study area (Delta state) showing the sample collection points [Source: Wikipedia and made by the authors]. 
determine the occurrence of antimicrobial residues using a four-plate test. Samples that were positive as macrolides were cleaned-up to obtain tylosin residue analytes using high-performance liquid chromatography (HPLC) to confirm the presence and determine the concentration of tylosin in fresh and fermented (nono) cow milk.

\section{Sample collection and transportation}

The study used $20 \mathrm{ml}$ each of 205 samples comprising 126 fresh milk and 79 fermented milk (nono) collected from Kwale, Ozoro, and Oleh Fulani milk-producing herds and dairy collection centers for a period of 8 weeks, using sterile universal sample bottles. The samples were immediately transported on ice cooler box to the Veterinary Public Health and Preventive Medicine laboratory of the University of Nigeria, Nsukka, for analysis. The samples were brought up to room temperature $\left(27^{\circ} \mathrm{C}\right)$ at the time of analysis.

\section{Screening for antimicrobial residue using four-plate} test

Screening was done using the European fourplate test, a conventional microbiological test for the detection of antimicrobials residues in foods of animal origin.

\section{Chemicals and reagents}

Mueller-Hinton agar (Oxoid), hydrochloric acid $(\mathrm{HCl})$, sodium hydroxide $\mathrm{Na}(\mathrm{OH})_{4}$, Bacillus subtilis (Merck Darmstadt, Germany, no. 64271), and Micrococcus luteus ATCC $^{\circledR} 10240$ strain were used.

\section{Procedure}

Four batches of Mueller-Hinton agar were prepared and adjusted to $\mathrm{pH} 6,7.2$, and 8 with dilute $\mathrm{HCl}$ as acid and $\mathrm{Na}(\mathrm{OH})_{4}$ as base. The first three plates with $\mathrm{pH} 6,7.2$, and 8 were seeded with $B$. subtilis which is ready to use suspension, the fourth plate, a $\mathrm{pH} 8$ plate, was seeded with $M$. luteus. Two holes were bored on each plate. A $50 \mu \mathrm{l}$ of the milk sample was inoculated in each hole and the other hole, $50 \mu \mathrm{l}$ of distilled water as negative control. The plates were incubated at $30^{\circ} \mathrm{C}$ for $18-24 \mathrm{~h}$, clear zone of inhibition with annular diameter of $\geq 2 \mathrm{~mm}$ indicates positive (Figure-2) for antimicrobial residues [22]. The plates seeded with $B$. subtilis at $\mathrm{pH} 6.0$ best detects $\beta$-lactams and tetracycline, at $\mathrm{pH} 7.2$ best detects sulfonamides, and at $\mathrm{pH} 8.0$ best detects aminoglycosides, while the plate seeded with $M$. luteus at $\mathrm{pH} 8.0$ best detects macrolides.

\section{Detection/confirmation of tylosin using HPLC}

Detecting the presence of tylosin and its concentration from the positive samples of $\mathrm{pH} 8.0$ plate seeded with M. luteus was done using HPLC, as described by Sokol et al. [23].

\section{Reagents and chemicals}

Tylosin tartrate standard was obtained from USP, 12601 Twin Brook Pkwy, Rockville, USA. Acetonitrile, methanol, and water HPLC grades were purchased

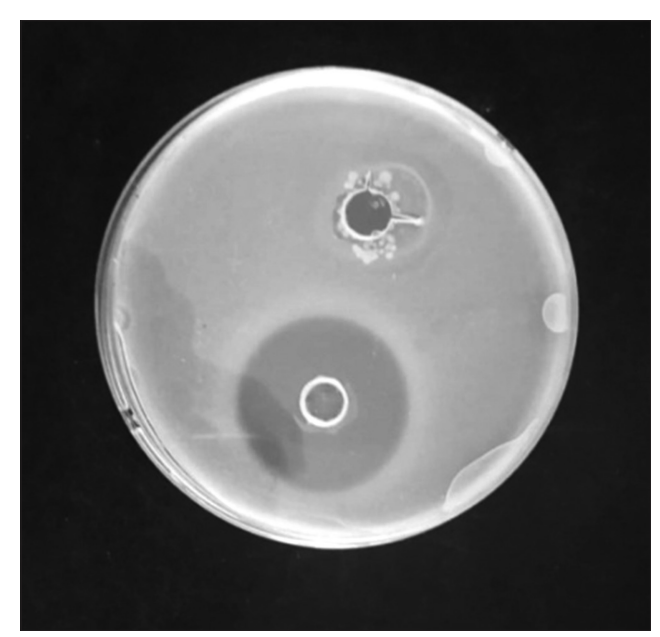

Figure-2: Four-plate test positive sample.

from Scharlau Chemicals, Poland. Potassium dihydrogenorthophosphoric acid, methanol Analar grade, 5 $\mathrm{ml}$ plain sample bottle packs, $5 \mathrm{ml}$ needle and syringes, $0.45 \mu \mathrm{m}$ Millipore filters were purchased from ABIKTOL, Nigeria (distributors for Market Research Society, UK). C18 solid-phase extraction (SPE) cartridges Bond Elute C18 (500 mg/3 ml) were purchased from Supelco Park, Bellefonte, USA.

\section{Tylosin standard solutions}

Tylosin stock solution $-1 \mathrm{mg} / \mathrm{ml}$ was prepared by dissolving $10 \mathrm{mg}$ tylosin tartrate in $10 \mathrm{ml}$ methanol and stored at $-18^{\circ} \mathrm{C}$. Working standard solutions for calibration curve were prepared by appropriate dilutions of the stock solution, using dilution factor. Fresh and nono milk tested and confirmed not to contain macrolide antibiotic residues (control) was used as sample blank for the preparation of matrix-matched calibration curve. For fortification, standard solutions were prepared by dissolving standard substance in methanol at concentrations of 40,20,10,5, and $2.5 \mathrm{mg} / \mathrm{ml}$.

\section{Sample preparation}

A $30 \mathrm{ml}$ of fresh/nono milk was centrifuged for $10 \mathrm{~min}$ at $3000 \mathrm{rpm}$ at $4^{\circ} \mathrm{C}$ to separate the fat layer. From the lower skim layer, $10 \mathrm{ml}$ was transferred to another centrifuge tube and $20 \mathrm{ml}$ acetonitrile was added. The solution was mixed and centrifuged for $10 \mathrm{~min}$ at $3000 \mathrm{rpm}$ and $4^{\circ} \mathrm{C}$. The extracted solvent layer was then decanted and diluted to $100 \mathrm{ml}$ with water and applied to the SEP-Pak Vac $\mathrm{C}_{18}$ cartridge.

\section{Clean-up procedure using SPE}

The SPE cartridges Bond Elute C18 $500 \mathrm{mg} / 3 \mathrm{ml}$ was activated with $2 \mathrm{ml}$ of methanol and $5 \mathrm{ml}$ of water. The cartridge was washed with $20 \mathrm{ml}$ of water at the flow of 1 drop $/ 2 \mathrm{~s}$ and allowed to dry. The extracted sample solution was loaded and allowed to elute from the cartridge with $3 \mathrm{ml}$ of methanol at the flow rate of $1 \mathrm{drop} / \mathrm{s}$. The solution was filtered using 0.45 micromillipore syringe filter. The samples were manually injected into the chromatographic system. 


\section{Chromatographic condition}

The chromatographic system used was an Agilent $^{\circledR}$ HPLC 1100 series system. Chromatographic analysis was performed with isocratic elution on Zorbax Eclipse XDB - C18 (150 mm×4.6 mm, $5 \mu \mathrm{m})$ analytical column at $30^{\circ} \mathrm{C}$. The mobile phase composed of acetonitrile and water (90:10) at the flow rate of $1.00 \mathrm{ml} / \mathrm{min}$. The volume injected was $20 \mu \mathrm{l}$ at ultraviolet detection of $292 \mathrm{~nm}$.

\section{Calculation of tylosin concentration from the stan- dard curve as determined by HPLC}

Figure-3 shows the results of the standard conc. and peak areas plotted as the standard curve produced a linear regression equation; $y=0.9604 x$, where $\mathrm{y}=$ peak area $(\mathrm{mAb})$ and $\mathrm{x}=$ conc. of tylosin, R2=correlation 0.9953, while Figure-4 shows positive tylosin sample.

\section{Data presentation and analysis}

Data generated are presented in percentages in tables and charts. GraphPad Prism 5 statistical software version 5.02 for Windows (GraphPad Software, La Jolla, California, USA, www.graphpad.com) was used for the analysis where Chi-square was used to determine the association between the occurrence of residues and the location/milk type. t-test was used to determine if there is a difference between the mean concentrations of tylosin in fresh milk and nono, $\mathrm{p}<0.05$.

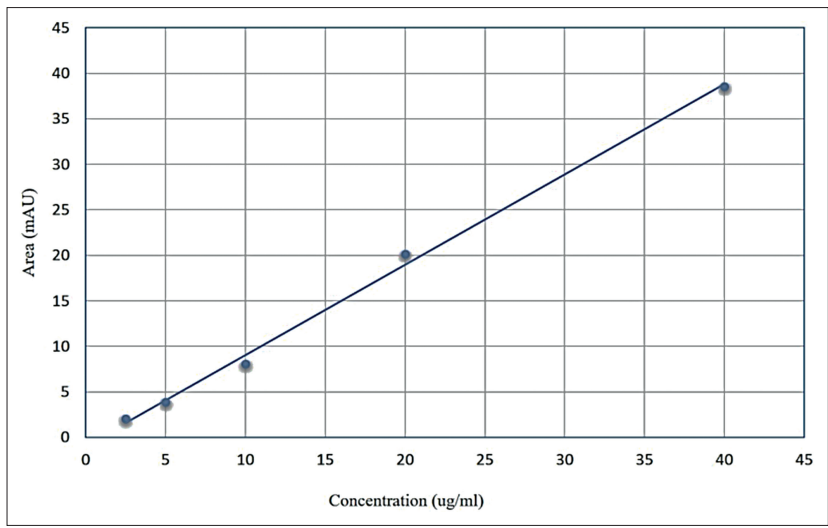

Figure-3: Tylosin analytical standard calibration curve.

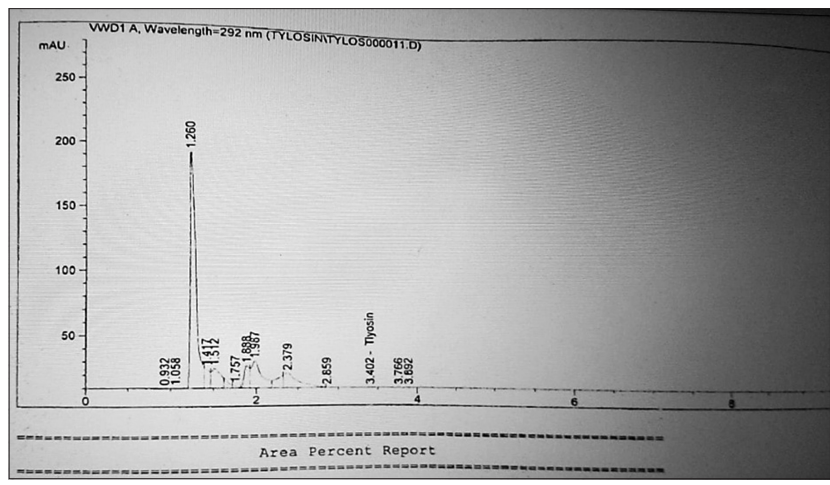

Figure-4: High-performance liquid chromatography chromatogram report of tylosin positive sample.

\section{Results}

Distribution of antimicrobial residues in fresh and nono milk samples in Kwale, Ozoro, and Oleh using four-plate test

A total of 205 dairy products were screened from three LGAs: Kwale, Ozoro, and Oleh of Delta state, comprising 126 fresh and 79 fermented (nono) milk, $163(79.5 \%)$ were positive for antibiotic residues. Ninety-six (76\%) out of 126 fresh milk and 67 (85\%) out of 79 fermented milk (nono) samples were positive for antimicrobial residues.

For location distribution, $22(88 \%)$ of 25 , $25(86 \%)$ of 29 , and $20(80 \%)$ of 25 nono samples from Ozoro, Kwale, and Oleh were positive for antimicrobial residues, respectively, while for fresh milk, $27(54 \%)$ of 50, $45(90 \%)$ of 50, and $24(92 \%)$ of 26 were positive for Ozoro, Kwale, and Oleh, respectively (Table-1). There was a significant (Chi-square $(2)=22.5 ; p<0.0001$ ) association between the occurrence of antimicrobial residues in fresh milk and the location of sample collection, with Ozoro having the lowest occurrence.

In the distribution of antimicrobial residues according to milk type, 96 (76\%) of fresh milk and $67(85 \%)$ of nono samples were positive for antimicrobial residue; however, the association between the occurrence of residue and the type of milk product was not significant $(\mathrm{p}=0.157)$.

\section{Tylosin residue in fresh milk and nono from the three local governments}

Thirty $(42 \%)$ out of the 71 presumptive macrolides containing fresh milk samples were confirmed tylosin, i.e., $24 \%$ of the whole fresh milk samples were positive for tylosin. Nine $(23 \%)$ of the 39 presumptive macrolides containing nono samples were confirmed tylosin. The overall mean tylosin concentration was $14.64 \pm 0.6896 \mu \mathrm{g} / 1$ and $7.97 \pm 0.2265 \mu \mathrm{g} / 1$ for fresh milk and nono, respectively (Table-2), and the difference in the mean concentrations was statistically $(\mathrm{t}(17)=7.18 ; \mathrm{p}<0.0001)$ significant.

\section{Discussion}

Milk is an important part of daily diet of all ages containing most balanced food compositions which provide essential nutrients for growth, maintenance, and development of body tissues. Being an important source of protein and other nutrients, it is in high demand, therefore should be free of contaminants and be safe for human consumption.

The study focused on determining the presence of antimicrobial residue in milk products (fresh milk and nono) that are ready to be consumed. The high prevalence of antibiotic residues in dairy products (fresh milk [76\%] and fermented milk [85\%]) in Delta state occurred at different $\mathrm{pH}$ levels of the frequent pattern tree (FPT), indicating the possible occurrence of beta-lactams, tetracyclines, aminoglycosides, and macrolides.

In Sweden, similar studies by Shitandi [10] and Shitandi and Sternesjo [24] have shown a range of the 
Table-1: Location distribution of antimicrobial residues in fermented (nono) and fresh milk in Delta state.

\begin{tabular}{|c|c|c|c|c|}
\hline \multirow[t]{3}{*}{ Location } & \multicolumn{4}{|c|}{ Sample type } \\
\hline & \multicolumn{2}{|c|}{ Fermented milk (nono) } & \multicolumn{2}{|c|}{ Fresh milk } \\
\hline & No sampled & No positive $(\%)$ & No sampled & No positive (\%) \\
\hline Ozoro & 25 & $22(88)$ & 50 & $27(50)$ \\
\hline Kwale & 29 & $25(86)$ & 50 & $45(90)$ \\
\hline Oleh & 25 & $20(80)$ & 26 & $24(92)$ \\
\hline Total & 79 & $67(84.8)$ & 126 & 96 (76) \\
\hline
\end{tabular}

Table-2: HPLC analysis of presumed macrolide from FPT for confirmation of tylosin in fermented (nono) and fresh milk in Delta state.

\begin{tabular}{|c|c|c|c|c|c|c|}
\hline \multirow[t]{3}{*}{ Location } & \multicolumn{6}{|c|}{ Sample type } \\
\hline & \multicolumn{3}{|c|}{ Fresh milk } & \multicolumn{3}{|c|}{ Fermented milk (nono) } \\
\hline & $\begin{array}{c}\text { FPT + ve (M.L } \\
\text { pH 8.0) }\end{array}$ & HPLC tylosin +ve & $\begin{array}{c}\text { Mean conc. } \\
(\mu \mathrm{g} / \mathrm{I})\end{array}$ & $\begin{array}{c}\text { FPT +ve } \\
(\text { M.L pH 8.0) }\end{array}$ & HPLC tylosin +ve & $\begin{array}{c}\text { Mean conc. } \\
(\mu \mathrm{g} / \mathrm{I})\end{array}$ \\
\hline Ozoro & 25 & 5 & 10.79 & 17 & 4 & 8.45 \\
\hline Kwale & 30 & 21 & 15.38 & 10 & 3 & 7.62 \\
\hline Oleh & 16 & 4 & 15.01 & 12 & 2 & 8.01 \\
\hline Total & 71 & 30 & $14.64 \pm 0.6896$ & 39 & 9 & $7.97 \pm 0.2265$ \\
\hline
\end{tabular}

HPLC $=$ High-performance liquid chromatography, FPT=Frequent pattern tree

prevalence of $9-11 \%$ which is much lower than the result obtained from the present study. The disparity is not unexpected because Sweden, being a member of the European Union, has strong legislation and enforcement against the prudent use of antimicrobials in food-producing animals which is lacking in Nigeria. Although there seem to be laws guarding against the use of antimicrobials in food animals in Nigeria, it is hardly if ever enforced [21]. Studies carried out in Ethiopia [25] and Kenya [26] revealed the detection of antimicrobial residues in $8.5 \%$ raw milk and a range of $9-16 \%$, respectively. The studies showed the low occurrence of antimicrobial residues probably because both countries have a more functional monitoring system of antimicrobials in slaughter animals. In Tanzania, antimicrobial residues were detected in $36 \%$ of marketed milk samples from milk supply chains in and around Mwanza and Dar es Salaam during 1999 and 2000 [27]. Mahmoudi et al. [28] recorded $29.16 \%$ in raw and pasteurized milk in Iran. In Ghana, a report showed that $35 \%$ of the raw milk marketed in two major cities, in Accra and Kumasi, were contaminated with antibiotics [29].

Regulations regarding veterinary drug use including withholding periods after antimicrobial use in food animals have been formulated, mainly to protect the public from the deleterious effects of the residues of these antimicrobials. Unfortunately, such regulations are rarely adhered to in some developing countries [29], especially Nigeria. This is buttressed by the work done by Olatoye et al. [4] in Southwest Nigeria which recorded overall prevalence of $42.6 \%$, with $40.8 \%, 24.4 \%$, and $62.3 \%$ in fresh milk, wara, and nono, respectively, and the high prevalence of $76 \%$ and $85 \%$ from fresh milk and nono, respectively, in this study. This implies that a large proportion of milk and milk products produced in the study area contains residues of one or more antibiotics. There is also a possibility of multi-antibiotic therapy for the treatment of infections, especially mastitis as most herders do not always have quick access to veterinarians; therefore, no sensitivity test done to narrow down on an antibiotic. The possibility of direct addition of antibiotics to bulk milk tanks for preservation is not ruled out. The degree of contamination of milk and dairy products with antimicrobial residues is dependent on the level of legislation and effectiveness of methods in tackling the indiscriminate use of antimicrobials in food animals in different countries [30]. The Ozoro samples had significantly lower occurrence of antimicrobial residues compared with Kwale and Oleh. Most of the samples collected from Ozoro were supplied to local fresh milk on producers from a ranch in a higher institution with an attached veterinarian. This shows that there is less indiscriminate use of antimicrobials in Ozoro, due to the intervention of a veterinarian. Apart from the assistance from the school veterinarian, Ozoro and Oleh, both have veterinary clinics run by qualified veterinarians which are sometimes patronized by herdsmen. This explains the lower number of positive samples compared with Kwale.

The high prevalence of antimicrobial residues recorded in this study indicates that consumers of locally produced fresh and nono milk are exposed to milk products with variable levels of antimicrobial residues, with the probability and risk of surpassing the acceptable daily intake for the various drugs.

The overall mean tylosin residue level in fresh milk $(14.64 \mu \mathrm{g} / \mathrm{l})$ obtained in this study is less than the Codex Alimentarius Commission maximum residue limits (MRLs) of $50 \mu \mathrm{g} / \mathrm{l}$ in milk and surprisingly 
lower than the reports by Ghidini et al. in Italy [31] $(62.40 \pm 5.50)$ and Khaskheli et al. in Pakistan [32] $(59.53 \mathrm{ug} / \mathrm{l})$. The presence of antibiotic residue in foods of animal origin above the MRL is recognized worldwide as being deleterious to human health [33].

In general, the high prevalence of antimicrobial residues in fresh milk and nono samples in this study may be attributed to the fact that residue monitoring program has not been put in place by the government; neither has there been any effort to sensitize the public on the dangers associated with residues in animal products [9]. Widespread and unrestricted use of different antibiotics in food animals without adequate diagnosis, prescription, and supervision by veterinarians contribute greatly to the deposit of these residues of these drugs in dairy products. Non-observance of withdrawal period of a drug after treatment cannot be ruled out, the results clearly show that herders and farmers do not wait for the withdrawal periods of the drug before milking; hence, the likely presence of antimicrobial residues above the specific MRLs shown by the inhibition zones much above $2 \mathrm{~mm}$ in the FPT.

Antibiotic residues enter the milk supply chain at farm level. Therefore, producers must realize the factors that lead to antibiotic residues in milk and how these residues can be avoided. Furthermore, the milk testing program should become a component of the quality control process centered on the farm.

\section{Conclusion}

More than half of the fresh and fermented milk sampled in this study contain antimicrobial residues. The possible detection of more than one antimicrobial in a sample is indicative of the use of more than one antimicrobial for treatment/prophylaxis. This is consequent on the easy availability of these antimicrobials over the counter and self-medication by the herdsmen, which means that the public is at risk of experiencing the health effects associated with consumption of such antimicrobial contaminated milk. The health risk associated with antimicrobial residues in milk and dairy products will continue to exist in Delta state and Nigeria as a whole until an effective residue monitoring program is legislated.

\section{Authors' Contributions}

EVE and OOS conceived the work, collected and analyzed the samples. EVE statistically analyzed the generated data. NJA and EVE drafted the manuscript. All the authors reviewed, edited, read, and approved the final manuscript.

\section{Acknowledgments}

We would like to appreciate the efforts of the laboratory technologists in the Department of Veterinary Public Health and Preventive Medicine, University of Nigeria, Nsukka. The authors did not receive any funds for this study.

\section{Competing Interests}

The authors declare that they have no competing interests.

\section{Publisher's Note}

Veterinary World remains neutral with regard to jurisdictional claims in published map and institutional affiliation.

\section{References}

1. Karim, G. (2008) Milk and Products. Tehran University Press, Persian. p10-30.

2. Osotimehin, K.O., Tijani, A.A. and Olukomogbon, E.O. (2006) An economic analysis of small scale dairy milk processing in Kogi State Nigeria. Livest. Res. Rural Dev., 18(11), Available from http://www.lrrd.org/lrrd18/11/ osot18157.htm. Retrieved on 28-02-2020.

3. Foramfera. (2012) Milk Production in Nigeria; the Opportunities. Available from: http://www.foramfera.com. Retrieved on 10-05-2016.

4. Olatoye, I.O., Daniel, O.F. and Ishola, S.A. (2016) Screening of antibiotics and chemical analysis of penicillin residue in fresh milk and traditional dairy products in Oyo state, Nigeria. Vet. World, 9(9): 948-954.

5. Olatoye, I.O. and Ogundipe, G.A.T. (2013) Quantitative analysis of oxytetracycline residue in beef and chicken meat from cities of southwest Nigeria. Bull. Anim. Health Prod. Afr., 61(1): 39-48.

6. Jayalakshmi, J., Paramasivam, M., Sasikala, M., Tamilam, T.V. and Sumithra, A. (2017) Review on antibiotic residues in animal products and its impact on environments and human health. J. Entomol. Zool. Stud., 5(3): 1446-1451.

7. Beyene, T. (2016) Veterinary drug residues in food-animal products: Its risk factors and potential effects on public health. J. Vet. Sci Technol., 7(1): 285.

8. Peters, R.J.B., Bolck, Y.J.C., Rutger, S.P., Stolker, A.A.M. and Nielen, M.W.F. (2009) Multiresidue screening of veterinary drugs in egg, fish and meat using high-resolution liquid chromatography accurate mass time-of-flight mass spectrometry. J. Chromatogr., 1216(46):8206-8216.

9. Kabir, J., Umoh, V.J., Audu-Okoh, E., Umoh, J.U. and Kwaga, J.K.P. (2004) Veterinary drug used in poultry farms and determination of antimicrobial drug residues in commercial eggs and slaughter chicken in Kaduna State, Nigeria. Food Control, 15(2): 99-105.

10. Shitandi, A. (2004) Risk Factors and Control Strategy of Antibiotic Residues in Milk at Farm Level in Kenya (Ph.D. Thesis). Uppsala University, Sweden.

11. Oladunjoye, B.G., Busari, A.A., Adekoya, A.W., Okoruwa, V.O. and Olanite, J.A. (2001) A survey of dairy production practices in the derived Savanna of Oyo State, Southwestern Nigeria. Niger. J. Anim. Prod., 28(2): 182-186.

12. Razzagh, M., Kivmars, A., Mahtab, V., Hamed, M. and Reza, V. (2014) Antibiotic residues in raw and pasteurized milk, Iran. J. Res. Health, 4(4): 884-889.

13. Adewuyi, G.O., Olatoye, O.I., Abafe, A.O., Otokpa, M.O. and Nkukut, M.K. (2011) High performance liquid chromatographic method for evaluation of two antibiotic residues in liver and muscles of broilers in Ibadan city, Southern Nigeria. J. Pharm. Biomed. Sci., 11(11): 1-4.

14. Padol, A.R., Malapure, C.D., Domple, V.D. and Kamdi, B.P. (2015) Occurrence, public health implications and detection of antibacterial drug residues in cow milk. Environ. Int. J. Sci. Technol., 10(1): 7-28.

15. Baynes, R.D., Dedonder, K., Kisell, L., Mzyk, L., Marmulak, T., Smith, G., Tell, L., Gehring, R., Davis, J., Riviere, J.E. (2016) Health concerns and management of select veterinary drug residues. Food Chem. Toxicol., 88: $112-122$. 
16. World Health Organization. (2017) Guidelines on Use of Medically Important Antimicrobials in Food-producing Animals. Available from: http://www.apps.who.int/iris/ bitstream/handle/10665/258970/9789241550130-eng.pdf; sequence $=1$. Retrieved on 15-11-2018.

17. Federal Ministries of Agriculture, Environment and Health. (2017) Antimicrobial Use and Resistance in Nigeria: Situation Analysis and Recommendations. Available from: https://www.ncdc.gov.ng/themes/common/docs/protocols/56_1510840387. Retrieved on 15-11-2018.

18. Ezenduka, E.V., Okorie-Kanu, O.J. and Nwanta, J.A. (2019) Comparative analysis of two microbiological tests in the detection of oxytetracycline residue in chicken using ELISA as gold standard. J. Immunoassay Immunochem., 40(6): 617-629.

19. Kebede, G., Zenebe, T., Disassa, H. and Tolosa, T. (2014) Review on detection of antimicrobial residues in raw bulk milk in dairy farms. Afr. J. Basic Appl. Sci., 6(4): 87-97.

20. Darwish, W.S., Eldaly, E.A., El-Abbasy, M.T., Ikenaka, Y., Nakayama, S. and Ishizuka, M. (2013) Antibiotic residues in food: The African scenario. Jpn. J. Vet. Res., 61(2): 13-22.

21. Ezenduka, E.V., Ike, O.S. and Anaelom, N.J. (2014) Rapid detection of antimicrobial residues in poultry: A consequence of non-prudent use of antimicrobials. Health, 6(2): 149-152.

22. Heitzman, R.J., editor. (1994) Veterinary Drug Residues. Residues in Food-Producing Animals and their Products: Reference Material and Methods. $2^{\text {nd }}$ ed. Commission of the European Communities, Blackwell Scientific Publications, Oxford, UK.

23. Sokol, J., Popelka, P. and Nagy, J. (2010) Determination of tylosin in food of animal origin by liquid chromatography. Folia Vet., 54(3): 167-171.

24. Shitandi, A. and Sternesjo, A. (2001) Detection of antimicrobial drug residues in Kenyan milk. J. Food Saf., 21(4): 205-268
25. Desalegne, A.S. (2008) Detection and Determination of Oxytetracycline and Penicillin G. Antibiotic Residue Level in Bovine Bulk Milk from Debrezeit and Nasareth Dairy Farm. Proceeding of the $1^{\text {st }}$ International Technology, Education and Environment Conference.

26. Kang'ethe, E.K., Aboge, G.O., Arimi, S.M., Kanja, K.W., Omore, A.O., McDermott, J.J. (2005) Investigation of the risk of consuming marketed milk with antimicrobial residues in Kenya. Food Control, 16(4): 349-355.

27. Kurwijila, I.R., Omore, A., Staal, S. and Mdoe, N.S. (2006) Investigation of the risk of exposure to antimicrobial residues present in marketed milk in Tanzania. J. Food Prot., 69(10): 2487-2492.

28. Mahmoudi, R., Amini, K., Vahabzade, M., Mir, H. and Vagef, R. (2014) Antibiotic residues in raw and pasteurized milk, Iran. J. Res. Health, 4(4): 884-889.

29. Aning, K.G., Donkor, E.S., Omore, A., Nurah, G.K., Osafo, E.L.K. and Staal, S. (2007) Risk of exposure to marketed milk with antimicrobial drug residues in Ghana. Open Food Sci. J., 1(1): 1-5.

30. Razia, K., Abdul, J.H., Shamim, A., Nazrul, I., Khorshed, A., Shariar, H., Mohammad, S.M. and Amirul, H. (2018) Validation of the declared withdrawal periods of antibiotics. Univ. J. Public Health, 6(1): 14-22.

31. Ghidini, S.M., Zanardi, E., Varisco, G. and Chizzolini, R. (2003) Residues of $\beta$ lactam antibiotics in bovine milk: Confirmatory analysis by liquid chromatography tends mass spectrometry after microbial assay screening. Food Addit. Contam., 20(6): 528-534.

32. Khaskheli, M., Malik, R.S., Aranin, M.A., Soomro, A.H. and Arain, H.H. (2008) Detection of $\beta$-lactams antibiotic residues in marketed residues. Pak. J. Nurt., 7(5): 682-685.

33. Singh, S., Shukla, S., Tandia, N., Kumar, N. and Paliwal, R. (2014) Antibiotic residues: A global challenge. Pharm. Sci. Monit., 5(3): 184-197. 